Hans Suter

Paul Klee and His Illness 


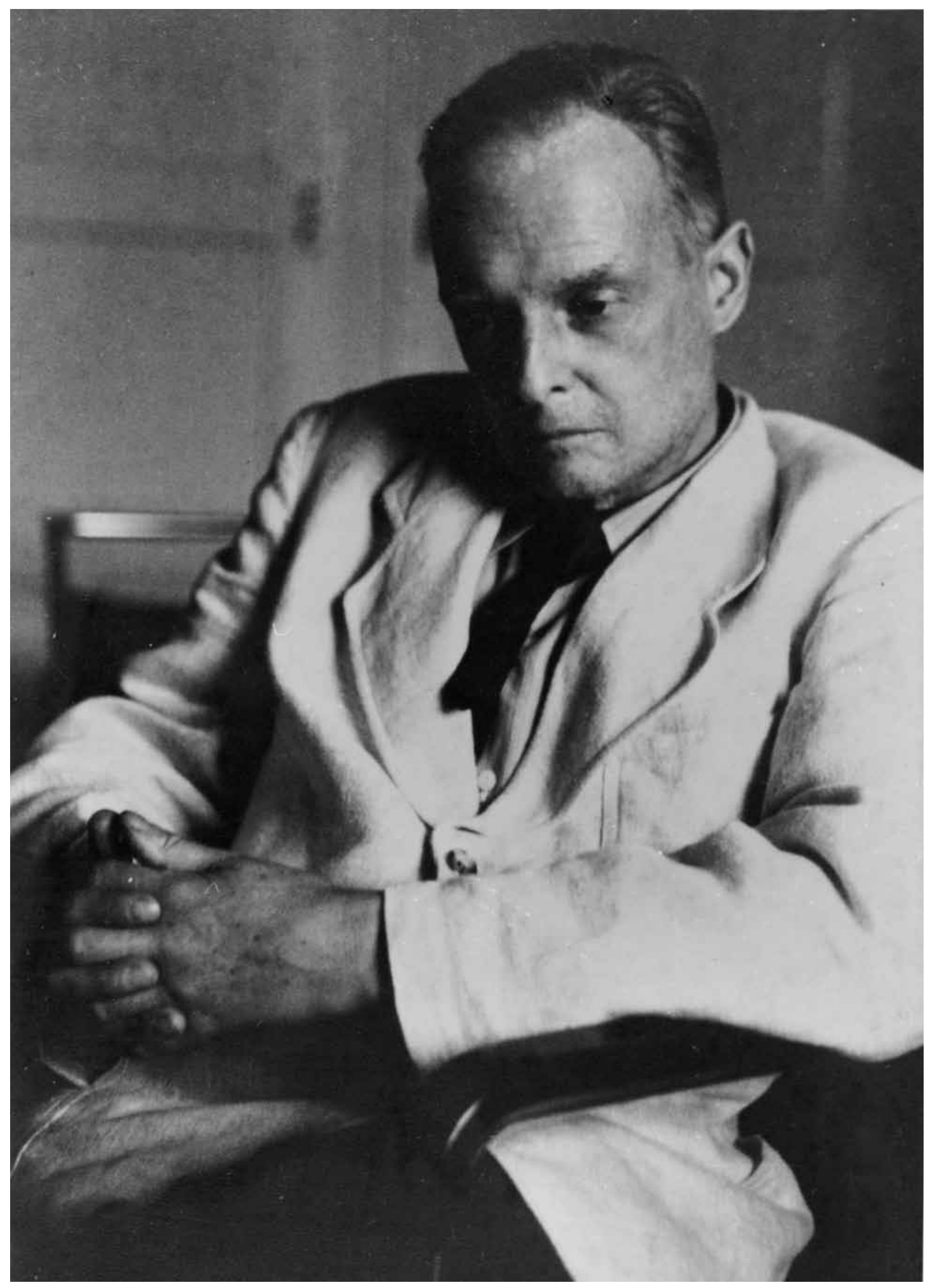




\section{Hans Suter}

\section{Paul Klee and His Illness}

\section{Bowed but Not Broken by Suffering and Adversity}

Translated from the German

by Gill McKay and Neil McKay

186 figures, 77 in color, and 2 tables, 2010 


\section{Contents}

Preface Aljoscha Klee

Foreword Hans Christoph von Tavel Introduction

Notes on Interpreting the Works of Art

1 Paul Klee's Life - Major Milestones

Early Years in Bern

Artistic Training in Munich and Italy, Sojourns in Bern and Munich

Trip to Tunisia, Military Service during World War I, Teaching, Journey to Egypt

Dismissal, Return to Bern, Isolation

Klee Exhibitions in Switzerland: Attracting Little Interest

'And My Sole Remaining Wish is to Be a Citizen of This City'

\section{Paul Klee's Illness}

First Symptoms - Persistent Bronchitis, Pneumonia, Pleurisy and Permanent Fatigue Measles?

Long Convalescence, Debility, Heart and Lung Complications A Possible Diagnosis: Scleroderma Overview of the Forms of Scleroderma Skin Disorders Mucous Membrane Disorders Raynaud's Syndrome Internal Organ Disorders

Digestive Tract Disorders • Lung Disorders • Cardiac

Disorders $\cdot$ Renal Disorders Death in Ticino

Discussion of the Symptoms and Course of Paul Klee's Illness How Was Paul Klee's Illness Treated? Other Medical Opinions on Paul Klee's Illness

F.-J. Beer - Lisbet Milling Pedersen and Henrik Permin • Philip Sandblom • Brigitta Danuser •

Michael Reiner - Christoph Morscher - E. Carwile LeRoy and Richard M. Silver - Gabriele Castenholz A Final Assessment of Paul Klee's Illness Paul Klee's Doctors 
4 The Effects of Adversity and Illness on Paul Klee's Mind and Work

Robust Psyche

What Could Have Caused Such a Serious IIIness?

Great Fortitude

Powers of Intuition, Conserving Energy, Concentrating on the Essentials

Belated Accolades

The Final Works

5 Klee's Late Work as a Reflection of His Personality, Social Environment, Illness and Proximity to Death

Isolation and Solitary Internalization

'Death Is Nothing Bad'

Work Full of Spirituality

'Art Is a Parable of Creation'

His Illness as a Constant Companion

A New Style of Extraordinary Intensity and Spontaneity

\section{Summary and Conclusion}

'Paul Klee and His Illness', Exhibition, Bern, 2005

Biographical Details of People Referred to 


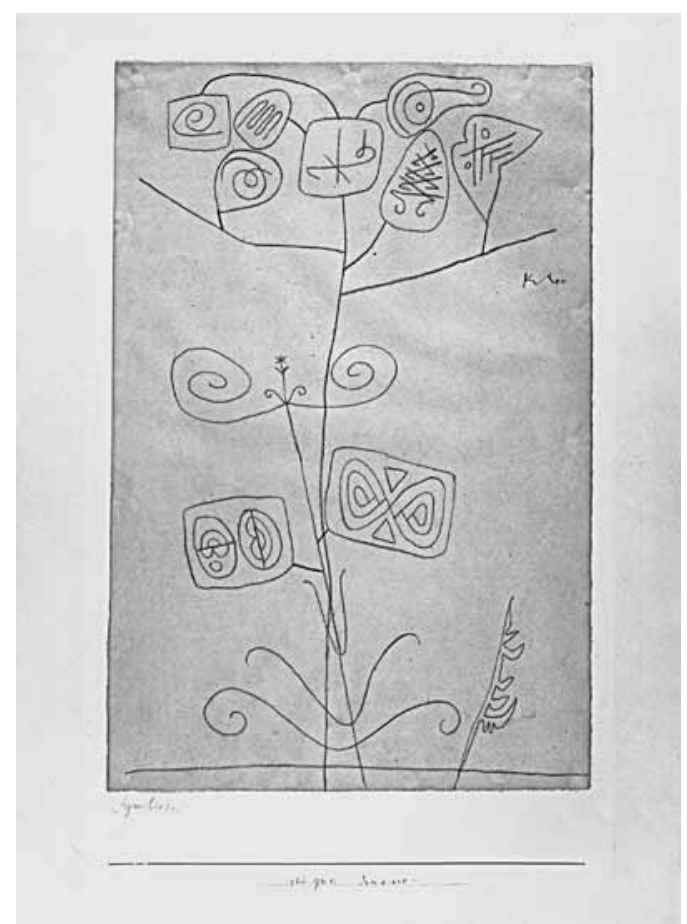

Fig. 1. Symbiosis, 1934, 131
For my wife Marlis Suter-Trächsel and our daughters Maja Wassmer-Suter and Christa Zaugg-Suter

In loving memory of our son and brother Gerhard Suter (1963-1986)

And for my teacher and friend Professor Dr. med. Alfred Krebs 


\section{Preface}

As the grandson of Paul Klee, faced with writing a preface to such a meticulously researched and written book and commenting on the tragedy contained in its pages, I find myself delving into a story that is really only relevant to me from a historical perspective. Sadly, I never had the chance to know my grandfather personally, but I have been able to draw on a whole latticework of personal memories. These memories are not directly linked to Paul Klee's illness, but they are a product of my parents' recollections and reflections on what they experienced. They were forced to stand by helplessly, watching and sharing in the artist's inevitable decline towards death. As a child growing up, I was not really able to fully understand my parents' stories and conversations about 'Buzzi'. But I gained a realization of the mystery of death and the artist's awareness of his own mortality, and this made an impression on me and preoccupied me during my formative years. For example, I was impressed by his determination to continue to achieve as much as his remaining time on earth would allow. Paul Klee still had so much more to say, and he knew it.

His later work, which was not only influenced by his illness, but which was done in defiance of that illness, is surely one of the most brilliant demonstrations of how suffering and sadness can be overcome through art and imagery, and in which, despite everything, irony can still shine through. I welcome this book as an important and sensitive contribution towards the appreciation of Klee's later work.

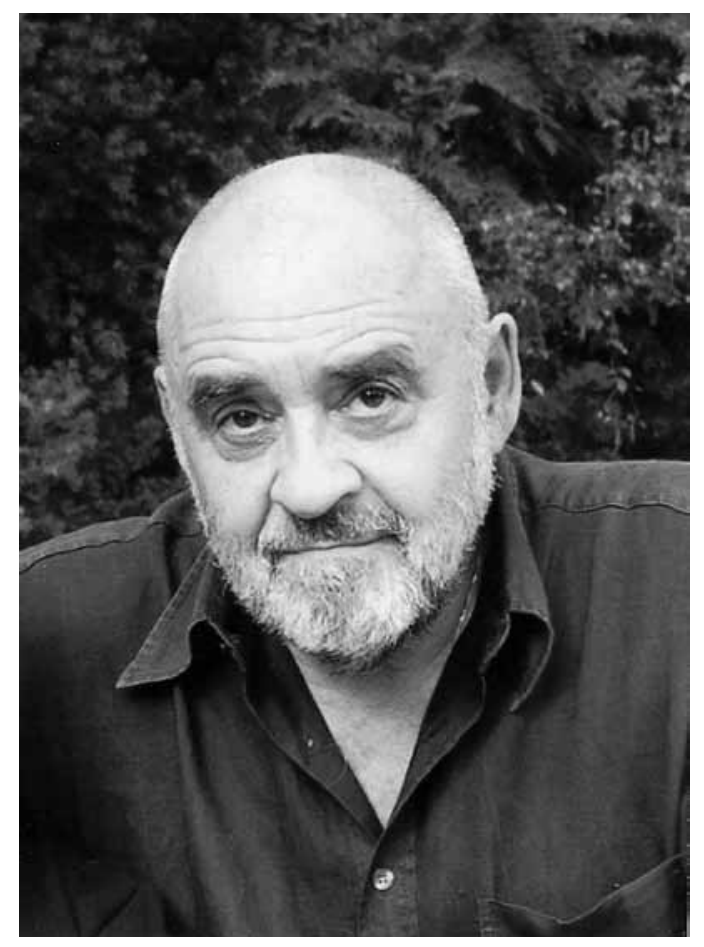

Fig. 2. Aljoscha Klee

Aljoscha Klee 


\section{Foreword}

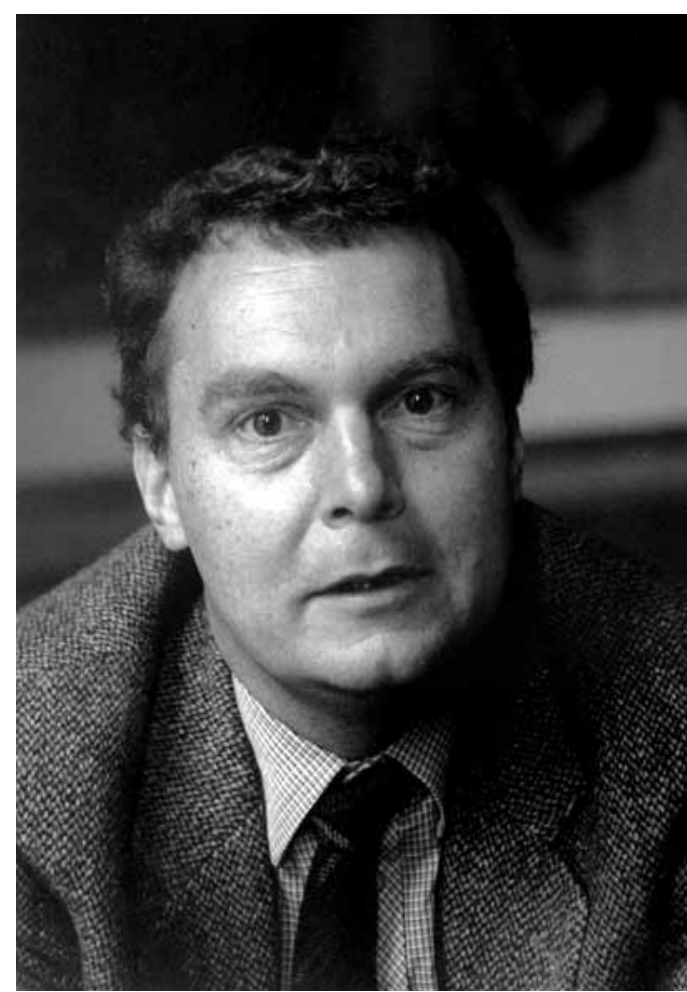

Fig. 3. Dr. Hans Christoph von Tavel, PhD
This publication occupies a special place amongst the many scholarly works on Paul Klee, as it fills a big gap in the studies done so far on an artist who is considered so important in the artistic and intellectual history of the 20th century. The subject of his illness has been brought up regularly in discussions of his later work, but for the most part without any specialist medical knowledge. Conversely, medical studies on the final years of the artist, who died in 1940 aged 60, often suffer from a lack of accurate research into the fateful progress of his illness and from a lack of knowledge about Klee's artistic work. The latter has only recently been catalogued in its entirety.

Hans Suter, who worked in Thun and its surrounding area as a specialist in dermatology and venereology, has been a collector and patron of the visual arts for decades. He began his research into the nature and development of Klee's illness more than 30 years ago. The lack of a medical history and the fact that the artist's death happened several decades earlier meant it was necessary to undertake extensive research. This was made particularly onerous by the fact that most of Klee's doctors, friends and collectors, as well as those who witnessed his illness, had by then also died. The artistic and human isolation that Klee suffered in Bern even before the outbreak of his illness - he was forced to leave Germany in 1933 - complicated matters even more. The author meets these challenges with profound medical knowledge, a comprehensive study of relevant literature and origi- 
nal source material, careful historical research and interviews with Klee's son Felix, other surviving contemporaries, and descendants of Klee's circle.

Doctors and local historians will be fascinated by this book's new insights into everyday medical practices in the university city of Bern in the 1930s, while art historians and art lovers will be absorbed by the newly discovered links and may make further links between the artist's work and his illness.

Hans Christoph von Tavel 